Arq. Bras. Med. Vet. Zootec., v.56, n.1, p.130-133, 2004

\title{
Comunicação
}

[Communication]

\section{Perfil de resistência antimicrobiana de cepas de Staphylococcus sp. isoladas de queijo tipo coalho}

[Antimicrobial resistance profile of Staphylococcus sp. strains isolated from type "coalho" cheese]

\author{
L.S. Rapini ${ }^{1 *}$, J.P. Teixeira ${ }^{2}$, N. E. Martins $^{3}$, M.M.O.P. Cerqueira ${ }^{2}$, M.R. Souza ${ }^{2}$, C.F.A.M. Penna ${ }^{2}$ \\ ${ }^{1}$ Pos-graduando - Escola de Veterinária da UFMG \\ ${ }^{2}$ Departamento de MedicinaVeterinária e Preventiva - EV/UFMG \\ ${ }^{3}$ Médico Veterinário
}

A partir de 1950, quando os antibióticos passaram a ser amplamente utilizados, iniciou-se o fenômeno de resistência bacteriana. Desde então, o problema de resistência aos antibióticos passou a representar importância considerável em saúde pública (Nawaz, 2002). Segundo dados da Food and Drug Association (Food..., 2002), aproximadamente $70 \%$ das bactérias que causam infecção hospitalar são resistentes a pelo menos uma das drogas comumente utilizadas para o tratamento das infecções. Muitas opções de drogas para o tratamento de infecções comuns estão se tornando limitadas, caras e, na maioria dos casos, inexistentes, sendo necessário, nesses casos, o uso de drogas potencialmente tóxicas ao homem que, na grande maioria das vezes, se encontram em fase experimental (National..., 2002).

A resistência antimicrobiana pode ser carreada pelo cromossomo bacteriano ou pelo cromossomo extra bacteriano denominado plasmídio (Food..., 2002). Bactérias resistentes a antibióticos preocupam uma vez que podem ser transmitidas ao homem pela ingestão de alimentos contaminados. No trato gastrointestinal elas podem transferir genes que

Recebido para publicação em 21 de novembro de 2002 Recebido para publicação, após modificações, em 21 de agosto de 2003

*Endereço para correspondência

Rua Bambuí, 752/204, B. Anchieta

30310-320 - Belo Horizonte, MG

E-mail: lusirapini@bol.com.br conferem a resistência antimicrobiana a outras bactérias (Witte, 2000) da própria espécie ou de espécies não relacionadas (FDA, 2002), patogênicas ou não.

Manipuladores de alimentos podem atuar como reservatório de Staphylococcus sp. A manipulação de queijos sem o devido controle higiênico-sanitário pode levar à sua contaminação por esses microrganismos (Souza et al., 1998). Este trabalho objetivou avaliar o perfil de resistência antimicrobiana de cepas de Staphylococcus sp. isoladas de queijos tipo coalho comercializados em praias nordestinas frente a oito antibióticos utilizados em medicina humana e veterinária.

As 45 cepas de Staphylococcus sp. foram isoladas de 10 amostras de queijo tipo coalho comercializadas em praias nordestinas. A análise microbiológica foi realizada na Fundação Ezequiel Dias, em Belo Horizonte, segundo Compendium... (1992). As cepas foram caracterizadas empregando-se $\mathrm{o}$ teste de coagulase livre segundo Lachica et al. (1980) e Lancette e Tatini (1992). A análise de susceptibilidade in vitro frente aos antimicrobianos foi realizada no Departamento de Tecnologia e Inspeção de Produtos de Origem Animal da Escola de Veterinária da UFMG. Empregou-se o método de difusão de antibióticos em disco segundo Bauer et al. (1966). As zonas de inibição foram medidas em milímetros e o biótipo foi classificado como resistente, intermediário (sensibilidade parcial) ou sensível ao antimicrobiano testado, conforme tabela 
disponibilizada pelo laboratório fabricante dos discos. Os antimicrobianos avaliados foram: penicilina $\mathrm{G}(\mathrm{PN})$ (10UI), gentamicina (GN) $(10 \mu \mathrm{g})$, eritromicina (ERI) $(15 \mu \mathrm{g})$, tetraciclina (TET) $(30 \mu \mathrm{g})$, sulfasotrin (SF) $(25 \mu \mathrm{g})$, oxacilina (OXA) (1 $\quad$ g), cefalotina (CF) $(30 \mu \mathrm{g})$ e vancomicina (VC) $(30 \mu \mathrm{g})$.

Os testes bioquímicos caracterizaram as 45 cepas de Staphylococcus sp. como: Staphylococcus aureus (22), Staphylococcus coagulase-positiva (7) e Staphylococcus coagulase-negativa (16).

De modo geral, verificou-se elevado percentual de resistência antimicrobiana das 45 cepas de Staphylococcus sp. aos oito antibióticos testados. A ordem decrescente de resistência foi: PN (100\%), TET (91\%), VC (75,5\%), GN $(71,1 \%)$, OXA $(66,7 \%)$, ERI $(60 \%)$, CF $(48,9 \%)$ e SF $(26,7 \%)$. A ordem decrescente de sensibilidade foi: $\mathrm{CF}(22,2 \%), \mathrm{GN}(11,1 \%), \mathrm{VC}(4,5 \%)$, OXA e SF $(2,2 \%)$ e ERI, TET e PN (0\%). Estes resultados contradizem os encontrados por Rapini et al. (2003), que verificaram elevada freqüência de sensibilidade das cepas de Staphylococcus sp. isoladas de leite cru, queijo e manipuladores de alimentos (narinas, mãos e orofaringe) frente a 12 antimicrobianos.

Observou-se elevado percentual de resistência múltipla das cepas aos antibióticos. Resistência a seis, sete e oito dos antibióticos testados foi observada, respectivamente, em nove (21\%), 17 $(32 \%)$ e seis $(13 \%)$ cepas (duas de S. aureus, duas de Staphylococcus coagulase-positiva e duas de Staphylococcus coagulase-negativa). Segundo Sena (2000), a elevada resistência múltipla a antibióticos representa um risco potencial à saúde pública e pode dificultar o tratamento de doenças, agravando quadros clínicos potencialmente curáveis.

Resistência à penicilina foi observada em 100\% das cepas de Staphylococcus sp. Estes resultados assemelharam-se aos descritos por Faria (1999) para cepas de $S$. aureus isoladas de leite cru, e superaram os descritos para cepas de $S$. aureus isoladas de leite cru (12,2\%) (Adesiyum, 1998), de queijos (50\%) (Oliveira et al.,1999) e (87\%) (Sena, 2000); das narinas, mãos e orofaringe de manipuladores de alimentos (90\%) (Maciel, 2001) e das mãos de ordenhadores $(53,6 \%)$ (Adesiyum, 1998). Foram também superiores aos descritos para cepas de Staphylococcus coagulase-negativa isoladas de queijos $(69,2 \%)$ (Oliveira et al., 1999), (74\%) (Sena, 2000) e (68\%) (Rapini et al., 2003). Apesar de praticamente todas as cepas de $S$. aureus terem apresentado sensibilidade a este antibiótico quando de sua introdução em 1940, seu uso indiscriminado ao longo dos anos desencadeou o fenômeno da resistência bacteriana (Panlilio, 1992). Esse autor citou que mais de $90 \%$ das cepas desse microrganismo apresentavam resistência não apenas à penicilina, mas também a outros antibióticos beta-lactâmicos.

Quanto à vancomicina, observou-se elevado percentual de resistência das cepas de $S$. aureus (90,9\%), Staphylococcus coagulase-positiva $(100 \%)$ e Staphylococcus coagulase-negativa (43,8\%). Estes resultados são superiores aos percentuais de resistência a essa droga pelas cepas de $S$. aureus (0\%) e Staphylococcus coagulase-negativa ( $25 \%$ ) obtidos por Oliveira et al. (1999) e por Sena (2000), respectivamente. Contudo, Rapini et al. (2003) verificaram 100\% de sensibilidade de cepas de Staphylococcus coagulase-negativa isoladas de manipuladores de alimentos e de leite cru, e $88 \%$ de isolados de queijos. Essa droga, aprovada somente para uso humano, durante anos foi considerada como o único antimicrobiano uniformemente efetivo contra cepas de $S$. aureus resistentes à meticilina. No entanto, seu primeiro relato de eficácia reduzida foi descrito no Japão em 1997, ao fracassar no combate de uma infecção humana causada pelo microrganismo (CDC, 2002).

Das 22 cepas de $S$. aureus, 90,9\% apresentaram resistência à $\mathrm{GN}, 86,4 \%$ à ERI e TET, $81,8 \%$ à OXA, $72,7 \%$ à $\mathrm{CF}$ e $22,7 \%$ ao $\mathrm{SF}$, enquanto que $77,3 \%$ apresentaram-se parcialmente sensíveis ao SF. Estes valores foram superiores aos descritos para PN (87,4\%), OXA $(45,7 \%)$ e ERI $(5,5 \%)$ (Sena, 2000). A sensibilidade à $\mathrm{GN}$ e ao $\mathrm{CF}$ obtida, respectivamente, por Oliveira et al. (1999) e Sena (2000) e por Oliveira et al.( 1999), foi $100 \%$.

Das sete cepas de Staphylococcus coagulase positiva, observou-se resistência de $100 \%$ à TET, $85,7 \%$ à GN e ERI e de $42,8 \%$ à SF, CF e OXA. Estes valores superaram as porcentagens de sensibilidade à GN e CF $(83,3 \%)$ e à ERI e SF $(100 \%)$ para cepas isoladas de leite cru (Rapini et al., 2003). 
Das 16 cepas de Staphylococcus coagulasenegativa, 93,8\% apresentaram resistência à TET, $81,2 \%$ à ERI, $56,2 \%$ à OXA, $43,8 \%$ à $\mathrm{GN}, 25 \%$ ao $\mathrm{SF}$ e $18,8 \%$ à $\mathrm{CF}$. Essas porcentagens superaram as descritas para PN $(69,2 \%)$ e $(74,4 \%)$ e para ERI $(25 \%)$ e $(2,3 \%)$ segundo Oliveira et al. (1999) e Sena (2000), respectivamente, para CF $(13,5 \%)$ e GN $(2 \%)$ (Oliveira et al.,1999) e para OXA (41,9\%) (Sena, 2000). Sensibilidades de cepas isoladas de queijos à GN (100\%) (Sena, 2000; Rapini et al., $2003)$ e ao SF (96\%) e à CF (84\%) (Rapini et al., 2003) foram também descritas.
Com base na elevada freqüência de resistência das cepas de Staphylococcus sp. isoladas de amostras de queijo tipo coalho comercializadas em praias nordestinas frente aos antibióticos testados, torna-se importante destacar a necessidade da adoção de medidas que controlem o uso indiscriminado de antibióticos pela população.

Palavras-chave: Staphylococcus, antibiograma, queijo tipo coalho

\begin{abstract}
The antimicrobial resistance profile of 45 Staphylococcus strains isolated from 10 samples of Brazilian type "coalho" cheese was evaluated against eight antibiotics used either in human or in veterinarian medicine. The tested antibiotics decreasing resistance degree was: penicillin (100.0\%), tetracycline $(91.0 \%)$, vancomycin $(75.5 \%)$, gentamicin $(71.1 \%)$, oxacillin $(66.7 \%)$, erythromycin $(60.0 \%)$, cephalothin (48.9\%) and sulphazothrin (26.7\%). The high frequency of Staphylococcus strains presenting resistance to the tested antibiotics, emphasizes the importance of the control of the abusive use of antibiotics by medical and veterinarian subjects.
\end{abstract}

Keywords: Staphylococcus, antibiogram, type "coalho" cheese

\section{REFERÊNCIAS BIBLIOGRÁFICAS}

ADESIYUM, A.A.; WEBB, L.A.; ROMAIN, H.T. Prevalence and characteristics of Staphylococcus aureus strains isolated from bulk and composite milk and cattle handlers. J. Food Prot., v.61, p.629-632, 1998.

BAUER, A.W.; KIRBY, W.M.M.; SHERRIS, J.C. et al. Antibiotic susceptibility testing by a standardized single disk method. Am. J. Clin. Pathol., v.45, p.493-496, 1966.

COMPENDIUM of methods for the examination of food. 3.ed. Washington: APHA, 1992.121p.

FARIA, J.F. Antimicrobial resistance of Staphylococcus isolated from raw milk. Rev. Fac. Cienc. Vet. Zulia, v.9, p.343-348, 1999.

FOOD and Drug Association. Antimicrobial resistance: a growing threat. Disponível em < www.fda.gov $>$ Acesso dia 17 de setembro de 2002.

LACHICA, R.V.F.; WEISS, K.F.; DEISEL, R.H. Relationships among coagulase, enterotoxin and heat stable deoxyribonuclease production by
Staphylococcus aureus. Appl. Microbiol., v.18, p.126-127, 1969.

LANCETTE, G.A.; TATINI, S.R. Staphylococcus aureus. In:__Compendium of methods for the microbiological examination of foods. 3.ed. Washington: APHA, 1992. p.533547.

MACIEL, C.H.P.; PINHEIRO, M.S.; FREEARIS, F.K. et al. Monitoramento de portadores de Staphylococcus aureus entre manipuladores de alimentos de uma indústria de fabricação de lingüiças. In: CONGRESSO ESTADUAL DE SAÚDE PÚBLICA E ALIMENTOS, 4., 2001, Nova Friburgo. Anais... Nova Friburgo: CRMV-RJ/CBMVHA, 2001. (Disquete)

NATIONAL Center for Disease Control and Prevention. Letter to health care providers from Maxine Hayes. Disponível em < www.cdc.gov > Acesso em 17 de setembro de 2002.

NAWAZ, M.S. Human health impact and regulatory issues involving antimicrobial resistance in the food animal production 
environment. Disponível em < www.fda.gov > Acesso em 17 de setembro de 2002.

OLIVEIRA, C.Z.F.; CORBIA, A.C.G.; NASCIMENTO, M.G.F. et al. Susceptibilidade antimicrobiana in vitro de bactérias do gênero Staphylococcus isoladas de Queijo Minas. Rev. Hig. Alim., v.13, p.30, 1999.

PANLILIO, A.L. Methicillin-resistant Staphylococcus aureus in U.S. hospitals, 19751991. Infect. Control Hosp. Epidemiol., v.13, p.582-586, 1992.

RAPINI, LS.; TEIXEIRA, J.P.; MARTINS, N.E. et al. Perfil antimicrobiano de cepas de Staphylococcus sp. isoladas de leite cru de cabra, queijo e manipuladores. Rev. Hig. Alim., v.17, p.162, 2003.
SENA, M.J. Perfil epidemiológico, resistência a antibióticos e aos conservantes nisina e sistema lactoperoxidase de Staphylococcus sp. isolado de queijos coalho comercializados em Recife/PE. 2000. 75f. Tese (Mestrado em Medicina Veterinária). Escola de Veterinária, Universidade Federal de Minas Gerais, Belo Horizonte

SOUZA, C.M.; BRAGANÇA, M.G.; COLI, M.C.M. et al. Manual de boas práticas de fabricação de pão de queijo. Belo Horizonte: CETEC, 1998. 54p.

WITTE, W. Ecological impact of antibiotic use in animals on different complex microflora: environment. Int. J. Antimicrobiol. Agents, v.14, p.321-325, 2000. 